\title{
Winter in water: Differential responses and the maintenance of biodiversity
}

Bailey C. McMeans ${ }^{1 *}$, Kevin S. McCann², Matthew M. Guzzo ${ }^{2}$, Timothy J. Bartley ${ }^{1,2}$, Carling

Bieg $^{2}$, Paul J. Blanchfield ${ }^{3,4}$, Timothy Fernandes ${ }^{1}$, Henrique Giacomini ${ }^{5}$, Trevor Middel ${ }^{5}$,

Michael D. Rennie ${ }^{4,6}$, Mark S. Ridgway ${ }^{5}$, Brian J. Shuter ${ }^{5,7}$

${ }^{1}$ University of Toronto Mississauga, Department of Biology, 3359 Mississauga Rd., Mississauga, ON L5L1C6

${ }^{2}$ University of Guelph, Department of Integrative Biology, 50 Stone Road E, Guelph, ON N1G 2W1

${ }^{3}$ Fisheries and Oceans Canada, 501 University Crescent Winnipeg MB, R3T 2N6

${ }^{4}$ IISD-Experimental Lakes Area, 111 Lombard Avenue, Winnipeg, MB R3B 0T4

${ }^{5}$ Harkness Laboratory of Fisheries Research, Aquatic Research and Monitoring Section, Ontario Ministry of Natural Resources, Trent University, Peterborough, ON, Canada

${ }^{6}$ Lakehead University, Department of Biology, 955 Oliver Road, Thunder Bay, ON P7B 5E1

${ }^{7}$ University of Toronto, Department of Ecology and Evolutionary Biology, 25 Harbord Street, Toronto, Ontario, Canada M5S 3G5

*Corresponding author: e-mail: bailey.mcmeans@utoronto.ca; mailing address: University of Toronto Mississauga, Department of Biology, 3359 Mississauga Rd., Mississauga, ON L5L1C6; phone: (905) 569-4959 


\begin{abstract}
The ecological consequences of winter in freshwater systems are an understudied but rapidly emerging research area. Here, we argue that winter periods of reduced temperature and light (and potentially oxygen and resources) could play an underappreciated role in mediating the coexistence of species. This may be especially true for temperate and subarctic lakes, where seasonal changes in the thermal environment might fundamentally structure species interactions. With climate change already shortening ice-covered periods on temperate and polar lakes, consideration of how winter conditions shape biotic interactions is urgently needed. Using freshwater fishes in northern temperate lakes as a case study, we demonstrate how physiological trait differences (e.g., thermal preference, light sensitivity) drive differential behavioral responses to winter among competing species. Specifically, some species have a higher capacity for winter activity than others. Existing and new theory is presented to argue that such differential responses to winter can promote species coexistence. Importantly, if winter is a driver of niche differences that weaken competition between relative to within species, then shrinking winter periods could threaten coexistence by tipping the scales in favor of certain sets of species over others.
\end{abstract}




\section{Introduction}

The role of temporal variation for promoting species coexistence has a long history in ecology (e.g., Paradox of the Plankton, Hutchinson 1961; Li and Chesson 2016). Just as species select for different resources and habitats, and in doing so partition their niche in space, species can also diverge in the timing of their activity, partitioning their niche in time (Chesson 2000). Contemporary theory asserts that temporal niche divergence in fluctuating environments can promote coexistence that would otherwise be impossible in a static environment (Adler et al. 2006; Angert et al. 2009; Chesson \& Huntly 1997; Tredennick et al. 2017). While much of this existing theory has focused on inter-annual variation, seasonal variation is being increasingly recognized for its role in coexistence (Mathias \& Chesson 2013; Mellard et al. 2019; Shimadzu et al. 2013; Tonkin et al. 2017; Treddnick et al. 2017). For example, competing species inhabiting the same environment and experiencing the same conditions can coexist by diverging in their annual patterns of metabolic activity (Szabo et al. 2016).

The onset and retreat of winter brings pronounced temperature variation across temperate and polar latitudes, with many lakes becoming ice-covered during winter. In these regions, winter in water is characterized by annual temperature minimums throughout the water column $\left(0\right.$ to $\left.4^{\circ} \mathrm{C}\right)$, reduced light, and potentially reduced oxygen and resource density (Shuter et al. 2012). Biota respond to these prominent seasonal changes in abiotic conditions in a variety of ways, including foraging, growing and reproducing at different times of the year. Because the metabolic rate of ectotherms is directly related to temperature, winter temperatures should ubiquitously suppress the ability of fish and other aquatic organisms to move, capture and digest prey, avoid predators, and grow (Hurst 2007). Yet, many groups of organisms, including amphipods (Werner 2006), zooplankton (Mariash et al. 2017) and fish (Shuter et al. 2012) 
contain species that remain active during winter. Some fishes, for example, are capable of maintaining or even gaining biomass under ice cover, owing to physiological adaptations that facilitate foraging in dark, cold conditions (Fig. 1A; Byström et al. 2006; French et al. 2014). Fishes that perform best at colder temperatures (i.e., those with colder thermal preferences) are expected to have a higher capacity for winter activity than fishes with warmer thermal preferences (Fig. 1B). Fishes that lack adaptations to low light and cold should be inefficient foragers during the winter, and are expected to adopt an overwintering strategy of suppressed activity (Fig. 1B; Watson et al. 2019). Because all ectotherms should be active and growing during warmer, brighter, open water periods (but within their upper thermal limit), divergent responses to cold, dark winters could be a mechanism for promoting niche partitioning and thermal performance trade-offs that favor different species at different times (Fig. 1C). If behavioral traits map to consumption and population growth rates, then trade-offs and divergent behaviors can promote coexistence by allowing species to recover from low densities when the environment turns in their favor (Angert et al. 2011; Li and Chesson 2016). Measuring changes in population density of multiple competing species through time could be used to quantify these density dependent effects ( $\mathrm{Li}$ and Chesson 2016). However, such data for fish communities are rare and consideration of how cold, ice-covered winter periods shape species interactions in aquatic ecosystems is in its infancy (Hampton et al. 2016; Helland et al. 2011; Salonen et al. 2009).

Here, we argue that the conditions imposed by winter and the different adaptations of species to succeed under winter conditions could play an underappreciated role in species coexistence. This winter-mediated species coexistence could be widespread, but is especially probable in northern temperate regions that experience winters of intermediate duration (Fig. 
1D). We first draw from theory to discuss how winter conditions could promote coexistence. We then use new and existing empirical data to demonstrate how freshwater fishes inhabiting northern temperate lakes diverge in their response to winter in ways that are consistent with previously described coexistence mechanisms. Next, we make the case that species likely diverge in time and space simultaneously, by both being active at different times and by partitioning resources in space. Finally, we present novel theory to explore when and where winter is most important for coexistence, and we pose these ideas as testable predictions for future work. Although winter is broadly viewed as a stressful period that limits ectotherm survival and growth, our perspective is that seasonal variation (and differential responses to winter periods, specifically), could also shape biotic interactions in ways that maintain diversity.

\section{Coexistence in fluctuating environments}

The ecological implications of temporally fluctuating conditions have intrigued ecologists for decades (Hutchinson 1961; Schoener 1982; Wiens 1977). Based on contemporary theory, non-equilibrium conditions alone do not promote coexistence simply by reducing population growth rates or decreasing the importance of competition (Chesson \& Huntly 1997; Hart \& Marshall 2013). Instead, to have a positive influence on coexistence, fluctuating conditions must either reduce the population growth rate of the dominant species (i.e., equalizing mechanisms) or generate opportunities for niche differentiation in space or time that weaken the strength of inter- vs. intraspecific competition (i.e., stabilizing mechanisms; Chesson 2000, 2018).

Equalizing mechanisms 
Harsh periods can influence coexistence by reducing differences in species average fitness if they disproportionately affect the dominant species (i.e., the equalizing mechanism; Chesson 2018; Chesson \& Huntly 1997). Here, the term 'species' in 'species average fitness' differentiates the concept from individual fitness, and 'average' refers to the average both: 1) across all individuals within a population of a particular species, and 2) across all environmental conditions experienced by that population (Chesson 2018). Species with high average fitness have a high growth rate and/or a low sensitivity to competition, giving them a competitive advantage over species with lower average fitness (Chesson 2000, 2018). Harsh periods, including but not restricted to winter, can operate on coexistence as an equalizing mechanism that reduces differences in species average fitness, thus slowing competitive exclusion and allowing otherwise competitively inferior species to persist for longer (Chesson \& Huntly 1997).

Importantly, while equalizing mechanisms can dampen the competitive edge of the dominant species, they do not singly guarantee stable coexistence. Instead, the species with the higher average fitness will eventually win and exclude the species with lower average fitness. Even if species have identical average fitness, neutral theory predicts they will eventually drift towards competitive exclusion, whose probability and/or timing would depend on population sizes and turnover rates (Chesson 2000; Hubbell 2011). Stabilizing mechanisms are required to overcome ecological drift to extinction or any differences in species average fitness (Adler et al. 2007; Chesson 2018; Tredennick et al. 2017).

\section{Stabilizing mechanisms}

Species can diverge in their niche by partitioning resources in space (Chase \& Leibold 2002; Macarthur \& Levins 1964), referred to as a fluctuation-independent coexistence 
mechanism (Chesson 2000). Species can also differentiate in the timing of when they use a shared resource (e.g., by feeding, growing, and reproducing at different times; Chesson 1985). Two such 'fluctuation-dependent' coexistence mechanisms are recognized: relative non-linearity and the storage effect (Chesson 2018). Relative non-linearity is when species differ in the shape of their functional response curves (i.e., one species has a more non-linear response to changes in resource density than the other species), favoring different species under different resource conditions (Armstrong \& McGehee 1980). The storage effect operates when species are able to 'store' during good times to sustain positive population growth during bad times. Both relative non-linearity and the storage effect operate via fluctuations (in resources or environmental conditions) that favor different species at different times, allowing coexistence that would be impossible in a static environment (Chesson 2018, 2020).

Empirical evidence supports both relative non-linearity and the storage effect as coexistence mechanisms operating in nature, albeit mostly for plants and plankton (Adler et al. 2006; Angert et al. 2011; Caceres 1997; Chesson et al. 2012; Descamps-Julien \&Gonzalez 2005; Zepeda \& Martorell 2019). Relative non-linearity could contribute most strongly to coexistence in species that diverge in life-history traits (e.g., fast vs. slow strategies) but otherwise have high niche overlap (Xiao \& Fussmann 2013). For the storage effect, differential responses to the environment (condition \#1 of the storage effect) tend to generate environment-competition covariance (condition \#2), and species with long-lived adults have buffered population growth (condition \#3; Chesson et al. 2012). Northern temperate freshwater fishes are known to vary in their life-history traits (e.g., spawn time, age at maturity, fecundity, lifespan) and span broad gradients in optimal environmental conditions for growth and metabolism (e.g. temperature; 
King et al. 1999). Fluctuation-dependent coexistence mechanisms could therefore operate in these communities.

\section{Winter in water: differential responses and the maintenance of biodiversity}

\section{Winter in northern temperate lakes}

Temperate latitudes are characterized by four distinct seasons. For waterbodies in this region, winter has been previously defined as the period of ice cover (Shuter et al. 2012).

Southern temperate lakes below about $40^{\circ} \mathrm{N}$ do not experience stable ice cover, so do not have 'true' winters, based on this definition. Lakes above about $60^{\circ} \mathrm{N}$ in subarctic and Arctic zones, on the other hand, experience long winters that can last for over half of the year, which can restrict biodiversity to only the most cold-adapted fishes. Northern temperate lakes - from about 40 to $60^{\circ} \mathrm{N}$ - fall between these two extremes, with ice cover lasting anywhere from 1 to 6 months depending on geographic location and elevation (Shuter et al. 2012). Northern temperate winters are therefore short enough to allow a phylogenetically and physiologically diverse fish assemblage to establish (unlike Arctic lakes), while also experiencing a unique set of conditions associated with stable ice cover (unlike southern temperate lakes; Shuter \& Post 1990).

Lakes $<61^{\circ} \mathrm{N}$ are also experiencing disproportionately rapid change due to climate warming and are at the highest risk of ice cover loss (Weyhenmeyer et al. 2011). Currently, most northern temperate lakes are dimictic, meaning warm surface waters stratify from cooler water at depth during summer, cold temperatures establish throughout the water column during winter, and the lake mixes twice per year (fall and spring). Warming temperatures are threatening to shift northern temperate lakes from ice-covered and dimictic to ice-free and monomictic (Weyhenmeyer et al. 2011). This is a concern because warmer and more consistently stratified 
water columns throughout the productive period will restrict cold-adapted fishes from accessing nearshore habitats and prey, with potentially negative consequences for their population growth (Guzzo et al. 2017; Plumb et al. 2014).

Along with cold temperatures, winter brings a shorter photoperiod that reduces light availability in the underlying water column. Ice and especially snow cover further attenuate the light available for primary production (Jewson et al. 2009) and foraging for visual predators (Blanchfield et al. 2009; Varpe et al. 2015). Ice cover also restricts atmospheric exchange, which can produce low oxygen conditions (Terzhevik et al. 2009) that affect fish survival, and therefore community structure (Hurst 2007; Tonn \& Magnuson 1982). Resources available for fishes could also change seasonally. Overwinter mortality of small-bodied minnows, for example, could reduce prey density for piscivores (Rennie et al. 2019), although very few studies have directly quantified prey density during ice cover. Even if resources remain at comparable densities between open water and ice cover, a particular resource may not be accessible during winter (e.g., due to low light; Blanchfield et al. 2009). However, some fishes are more tolerant of winter conditions than others, remaining active and successfully foraging despite the cold and dark conditions.

\section{Differential responses to winter in fish}

Temperature is a fundamental niche axis for ectotherms that dictates all major metabolic processes (Fry 1947). All organisms have a temperature range over which they perform optimally with respect to their activity, growth and reproduction (Casselman 2002; Hokanson 1977; Pörtner 2007). Temperature preferences of freshwater fishes fall along a continuous spectrum, but three discrete categories are typically used based on their optimal thermal 
performance temperatures: the cold-water, the cool-water and warm-water guilds (Fig. 2A;

Casselman 2002; Hokanson 1977; Magnuson et al. 1979). Fig. 2A illustrates the guild membership, temperature preference and upper thermal limit for a sample of common North American freshwater fishes, using typical threshold values for each guild $\left(<17.5^{\circ} \mathrm{C}\right.$ for coldwater, 17.5 to $<25^{\circ} \mathrm{C}$ for cool-water, and $>25^{\circ} \mathrm{C}$ for warm-water). Thermal preferences reflect the adaptation of: 1) molecular processes (e.g., stability vs. flexibility of proteins, cell membranes, DNA and RNA; Pörtner 2007), and 2) capacity to supply oxygen at the whole organism level (e.g., aerobic scope; Pörtner 2002) to a particular temperature range. Because winter temperatures of $4^{\circ} \mathrm{C}$ are below the thermal optima of nearly all North America freshwater fishes (Fig. 2A), such temperatures should generally reduce the aerobic scope of all species. As a result, available thermal habitat to achieve optimal growth is typically plentiful for all fish of all thermal guilds at some time during open water, but absent during winter.

Despite winter being a potentially stressful time for all fish, physiological adaptations allow for sustained winter activity in some species. These adaptations include hypertrophy of the heart and liver, increased mitochondrial density and function, improved vision, and high growth efficiency (Shuter et al. 2012; Tschantz et al. 2002). Adaptations to activity in the cold do come with a cost (e.g., greater mitochondrial density can increase standard metabolic rate; Pörtner 2002), but these metabolic costs should be lower for species with lower thermal preferences compared to species with warmer thermal preferences (Shuter et al. 2012). This pattern is suggested by Fig. 2B, showing that thermal breadth (i.e. upper thermal limit - thermal preference) narrows as thermal preference increases. The cost of optimizing to a particular temperature is also thought to generate thermal performance trade-offs, meaning a species cannot perform optimally across all temperatures (Kingsolver 2009; Portner 2007). The thermal metrics 
for North American freshwater fishes provide strong empirical support for such thermal performance trade-offs. First, species with colder thermal preferences have lower upper thermal limits (Fig. 2A). In fact, upper lethal temperatures for many cold-water fish are actually less than the preferred temperatures for many warm-water fish (Fig. 2A). Increased performance at lower temperatures therefore appears to trade-off with reduced performance at higher temperatures (Fig. 1C, 2A). Additionally, increased performance at higher temperatures appears to trade off with lower thermal breadth, suggesting a trade-off between thermal preference and thermal breadth (Fig. 2B). Cold water fish should therefore be more successful across seasons compared to warm water fish, whose performance is limited during winter. We now present two case studies to explore how different capacities for winter activity and trade-offs between activity in open water vs. ice cover manifest in particular species pairs that belong to different (case study \#1) or similar (case study \#2) thermal guilds.

\section{Case Study \#1}

The first case study presents data from a northern temperate lake in Ontario, Canada for smallmouth bass (Micropterus dolomieu) and lake trout (Salvelinus namaycush), which belong to the warm-water and cold-water thermal guilds, respectively (Fig 2A). This lake lacks an offshore forage fish, meaning the only prey fish for consumption by piscivores are found in the littoral zone. In lakes supporting this type of food web, lake trout and smallmouth bass have overlapping diets that include invertebrates and littoral forage fish (Box 1). Acoustic telemetry data (explained in detail in SI S1) confirm that during cold months, lake trout continue to be active and move inshore, overlapping in the littoral habitat used by smallmouth bass (Fig. 3A, B, C). However, smallmouth bass, but not lake trout, reduce their activity rates in winter as spatial overlap increases (Fig. 3D), suggesting temporal niche partitioning occurs between these two 
potential competitors (Box 1). Differences in growth rates further suggests that different seasons favor different species (Fig. 4, Box 1), consistent with the necessary conditions for temporal fluctuation-depending coexistence.

$<<$ insert Box 1, text found at end of main text $>>$

\section{Case study \#2}

The second case study presents data from a northern temperate lake in Northwest Territories, Canada for lake trout and burbot (Lota lota), which both have cold thermal preferences (Box 2). These species segregate spatially throughout much of the year (Fig. 5A, C) but have similar diets both being piscivores (Guzzo et al. 2016). In accordance with their colder thermal preferences, previous work has illustrated that both of these species can be active during winter (Blanchfield et al. 2009; Hölker et al. 2004), suggesting interspecific competition could be high throughout the year, including under winter ice cover. Indeed, acoustic telemetry data demonstrate that these two species overlap in their patterns of annual activity (i.e., both reduce activity in summer and maintain activity in winter, Box 2, Fig. 5D). Regardless, lake trout and burbot clearly show temporally distinct niches that likely reduce interspecific relative to intraspecific competition. Lake trout spawn in the fall and are known to forage actively in the spring, whereas burbot are actively foraging and spawn in the winter (Hölker et al. 2004, Cott et al. 2013, Guzzo et al. 2016). Shorter (darker) days and ice and snow cover during winter might, therefore, favor the typically nocturnal burbot over the more visually-reliant lake trout (Box 2). As the ice thins and melts in the early spring, lake trout and burbot would be expected to exploit suitable conditions for foraging and growth, but before warm-adapted species become active (e.g., smallmouth bass; Box 1). 
$<<$ insert Box 2, text found at end of main text $>>$

Other examples of seasonally variable biotic interactions

Fluctuating temperatures can alter the identity of the competitive dominant between other pairs of fish species, too. For example, European perch (Perca fluviatilis) had higher prey capture success and were competitively superior at cooler temperatures closer to their optimum, compared to roach (Rutilus rutilus; Persson 1987). Conversely, roach performed better at warmer temperatures closer to their optimum (Persson 1987). Other examples from the literature confirm that seasonal cycles of photoperiod and light availability can facilitate cycles of competitive advantage among fishes with similar thermal preferences, but divergent requirements for light. In European lakes, brown trout (Salmo trutta) and Arctic charr (Salvelinus alpinus) are both coldwater salmonids that overlap in their littoral habitat and dietary preferences (Amundsen \& Knudsen 2009). Brown trout are considered the superior competitor and appear capable of restricting Arctic charr from accessing littoral habitats during summer (Eloranta et al. 2013). Under ice cover, however, Arctic charr move into the littoral habitat (Amundsen \& Knudsen 2009) and appear to be the superior competitor, having a higher capacity for successful foraging in the dark compared to brown trout (Helland et al. 2011).

The examples we have highlighted so far illustrate that winter behavior can vary both between and within thermal guilds. Organisms cannot succeed and perform best under all conditions, especially when conditions vary across seasons (Kingsolver 2009, Pörtner 2002). For example, species that invest heavily in rapid growth do not tend to invest in physiological adaptations for coping with sub-optimal periods (Angert et al. 2009; Chesson \& Huntly 1997). Performance at high temperatures can trade-off with performance at cold temperatures, and 
having a wide thermal breadth can trade-off with maximum performance at optimal temperatures (Kingsolver 2009). Physiological adaptations that favor active winter foraging and a wider thermal breadth could, therefore, limit these species ability to use the warmest, brightest, and more productive region of lake (i.e., nearshore littoral zone) during summer (Fig. 2). Next, we discuss how these trade-offs could play a role in coexistence.

\section{Coexistence in time and the role of winter}

Trade-offs that favor different species at different times and generate differential demographic responses to the environment are the basis for fluctuation-dependent coexistence (Angert et al. 2009; Chesson 2000; Miller and Klausmeier 2017). We lack data on the competitive response, functional response, or average fitness of our case study species to properly test for a particular coexistence mechanism in northern temperate lakes. However, our empirical examples (see Boxes 1 and 2) appear to meet the three ingredients of the storage effect. Fish are expected to demonstrate differential demographic responses to the environment (i.e., condition \#1) because their activity, growth and reproduction are favored and cued by different environmental conditions (Shuter et al. 2012). We also expect that different thermal adaptations in fishes should alter interspecific competitive abilities across seasons. Cold-adapted species should be better interspecific competitors in the winter, while warm-adapted species should be better interspecific competitors in the summer. All else equal, these adaptations should form the basis for weakened environment-competition covariance at low densities (condition \#2), such that cold water species can invade from low densities (due to weakened intraspecific competition) under winter conditions (when they are better interspecific competitors), while warm water species can invade from low densities during warmer seasons. Longer life expectancies would buffer fish population growth from 'bad' times when the environment is not 
favorable and competition is high (i.e., condition \#3). Of course, other coexistence mechanisms are possible, and the storage effect and relative nonlinearity are not mutually exclusive (Yuan \& Chesson 2015). For example, different growth responses to winter duration could also reflect relative nonlinearity of species functional responses. A trade-off between growth capacity in open water and winter activity could also suggest winter acts as an equalizing mechanism by reducing the population growth of the species with higher growth capacity.

Based on the above arguments, our perspective is that winter, which is historically underrepresented in ecology, could play an important role in weakening interspecific relative to intraspecific competition and promoting coexistence through a variety of theoretically supported mechanisms. We are not arguing that winter is the only season that is important for coexistence; competition might actually peak during other seasons when spatial overlap is highest (e.g., during fall and spring when lake trout and smallmouth bass cross paths, Fig. 3B, C). Seasons other than winter can also be harsh and stressful to fish (e.g., summer can cause thermal or oxidative stress), and fish clearly diverge in their foraging behavior and life history in lakes that lack ice-covered winters, meaning that winter is not a prerequisite for fish to coexist. Our overarching goal, here, is to bring attention to two key points:

1) Biotic interactions between species can change dramatically throughout the year with seasonal changes in environmental conditions.

2) Ice-covered periods, which are broadly perceived as a stressor for all fishes, could also play a unique role in generating differential responses among competing species.

While all fishes are expected to be active during open water periods and generally able to find and use habitat within optimal temperatures, the unique conditions of winter in ice-covered 
lakes seem to result in divergent behaviors that include both winter active and inactive species.

The persistent cold, dark, low-resource, or low-oxygen conditions of winter drive species with warmer thermal preferences to suppress their activity rates and reduce their foraging (by accumulating lipid reserves before winter or relying on energy conservation due to suppressed metabolic rates or both; Mackereth et al. 1999; Secor \& Carey 2011, Shuter et al. 2012). Some evidence suggests, for example, that warm-water fishes in southern temperate lakes with warmer, shorter and more sporadic winters do not enter a period of consistently reduced activity (Fullerton et al. 2000). For dark periods to reduce the performance of species tailored to thrive in bright, open waters (Helland et al. 2011; Vogel \& Beauchamp 1999) stable periods of snow and ice cover are required to suppress light beyond that which is associated with photoperiodic reductions. Increased water temperature and light (i.e., decreased snow and ice) due to climate change could alter competitive advantages during winter by increasing activity rates or prey capture success for species that would otherwise have suppressed winter performance. This is akin to species increasing their niche overlap in time. Given its predictability to organisms, winter could be a strong generator of divergent ecological behaviors among species (i.e., timing of reproduction, growth, activity) and performance trade-offs. If such trade-offs underpin coexistence and tend to organize around predictable variation in space (e.g., littoral versus pelagic) and time (e.g., winter versus summer), it is critical that we deepen our understanding of ecological processes occurring during winter. We now consider how winter and temporal niche divergence might play a widespread role in coexistence even in systems where species also spatially partition resources.

\section{A case for multiple coexistence mechanisms}


To this point, we have focused on coexistence that arises by species partitioning along seasonal axes by diverging in the timing of their activity. However, biodiversity in complex, natural systems is almost certainly sustained by species partitioning along multiple niche axes (for general theory on space and time, see Chesson 2020). Mobile species are readily able to avoid competition by spatiotemporally partitioning their environment (e.g., by moving to particular locations during certain seasons that contain lower densities of competitors; Jeltsch et al. 2013). Given the high mobility and generalist diet of many fishes, spatial and temporal niche partitioning likely operate in tandem. For example, mobile aquatic taxa shift their habitat seasonally in response to changes in temperature and prey density (Diez et al. 2018; Holbrook and Schmitt 1989) or select for prey types not shared by their competitors during each season (Amundsen \& Knudsen 2009; Hayden et al. 2015). Even in our case studies, competing species pairs diverge not only in their annual patterns of activity but also their habitat use (Box 1, 2). Coexistence in fish communities could therefore be maintained by divergence in both time and space (Chesson 2020).

Recent theoretical and empirical studies have also concluded that species diverge along multiple niche axes, and that multiple coexistence mechanisms likely operate simultaneously to sustain nature's diversity (Chesson et al. 2012; Chesson 2018, 2019, 2020; Ellner et al. 2016; Zepeda \& Martorell 2019). Using different resources and using the same resource at different times would both be expected to stabilize coexistence for the same reason: both dampen the strength of interspecific relative to intraspecific competition (Chesson 2000; Chesson \& Huntely 1997; Chesson 1985). The existence of multiple coexistence mechanisms means that, even if species exhibit some overlap in temporal activity patterns, species can still coexist by partitioning resources in space at any given time. Performance trade-offs (e.g., between summer 
growth capacity and winter activity) need therefore not be perfectly balanced to play a role in coexistence. For example, species that are well-adapted to warm productive periods could also be capable of low-level winter activity, which would drive some overlap in annual activity patterns with a winter-active species. Cold-water species that are capable of winter activity could have similar activity rates to warm-water species in summer, albeit in different habitats (e.g., lake trout and smallmouth bass, Box 2). Divergence along multiple niche axes could make coexistence possible in these situations, where some overlap occurs along one axis.

Importantly, if seasonal variation and harsh winter periods drive species to diverge along any niche axis, whether that be in the timing of foraging, reproduction or growth, or in their habitat and resource selection, it could be an under-recognized player operating in a suite of coexistence mechanisms. In other words, winter might play a role not only in driving divergence in activity patterns, but also in species selecting for different resources and habitats (Schoener 1982). Shorter, weaker winters already arising in northern temperate lakes (Weyhenmeyer et al. 2011, Sharma et al. 2019) could therefore threaten coexistence if they cause species to converge in their niches, either by causing species to become more winter-active when they would otherwise be inactive, or by causing species to overlap in their resource use. As a step towards considering the biodiversity consequences of ice cover loss on northern temperate lakes, we developed new theory that explores under what contexts winter might play the most important role in coexistence.

\section{Winter's context dependency: when and where does winter matter most for coexistence?}

Different winter behaviors have different consequences for individual survival, growth, and therefore, population dynamics (Hurst 2007). Foraging in the winter increases both 
metabolic costs and potential energy gain, which could have either positive or negative consequences for growth during both winter, but also during the next growing period (Amundsen \& Knudsen 2009; Byström et al. 2006; Cunjak et al. 1987; French et al. 2014). In lake trout, for example, long winters appear to have minimal impact on individual growth in lakes that contain offshore forage fish, yet suppress lake trout growth in lakes lacking offshore forage fish (Fig. 4A, C). Access to a high-quality prey during open water months, which increases lake trout growth and condition (Cruz-Font et al. 2019), could carry over and help promote more sustained growth in winter, although more work is needed to explore this idea. Compared to winter-active species, winter-inactive species suppress metabolic costs through reduced activity and feeding and therefore have little capacity for overwinter growth (Micucci et al. 2003). Food availability, predation, disease, starvation, and competition could all drive variation in overwinter growth and mortality within and among winter active and inactive strategies (Garvey et al. 2004; Hurst 2007). In small lakes, for example, resources may be limited and competition more amplified due to higher spatial overlap between competing species (Hayden et al. 2014, McCann et al. 2005). The consequences imposed by winter should therefore be expected to vary substantially among different fish species (Shuter et al. 2012), and from lake to lake among different populations.

Given the paucity of winter data, it is unknown if and how fish growth and competition during winter vary with characteristics like lake size and productivity in ways that influence coexistence. To begin to address this, we developed new theory that explores how coexistence in a seasonal environment is dependent on the duration of winter under cases of both weak and strong interspecific competition (corresponding to coexistence and competitive exclusion, respectively; Box 3), as might be expected in large and small lakes, for example. Given the 
variable outcomes of winter for fish activity and growth across species and populations, we also consider coexistence outcomes when the two competing species have either synchronized (i.e., both decline in winter to various degrees) or asynchronized growth dynamics (i.e., the winteradapted species grows in winter, Fig. S2). Below, we highlight two important points from this theory, which is explained in Box 3.

$<<$ insert Box 3, text found at end of main text $>>$

Winter duration and the strength of competition impact species coexistence

The length of winter impacts species coexistence generally in that it can drive the loss of diversity or, at the least, produce large changes in the density of competing species based on our theory (Fig. 6). Our theory also suggests the intriguing case where seasonality can be entirely responsible for coexistence given the empirically supported trade-offs whereby the species that is most successful in winter is less successful in open water (Fig. 2; Portner 2007; Lancaster et al. 2017). Note, the strong-strong case by definition does not give coexistence without seasonality (Fig. 6D). This winter-mediated species coexistence is interesting because it suggests climate change that alters winter length and ice cover duration, as is predicted to continue across northern temperate lakes (Weyhenmeyer et al. 2011), even modestly, ought to potentially drive significant and rapid loss of winter-adapted species (Fig. 6C). This same sensitivity to seasonal length also occurs for other cases (Fig. 6), so the impacts of season are potentially potent even where only one season mediates coexistence.

Coexistence between two species was, however, sensitive to the strength of interspecific competition. When interspecific competition was weak in both seasons (i.e., each season meets coexistence conditions), the two species coexisted across a broader range of winter durations 
(Fig. 6A). Weak competition might be expected in large lakes, where spatial overlap among competitors could be low, and where species have opportunities to more effectively partition resources (Hayden et al. 2014, McCann et al. 2005). For example, lake trout reduce their reliance on littoral foraging as lake size increases (Tunney et al. 2012), which could reduce their resource overlap and potential competition with littoral fishes like smallmouth bass (Vander Zanden and Rasmussen 1996, Vander Zanden et al. 1999). Large lakes might also be expected to have more habitat refuges for cold-adapted fishes, because larger lakes are typically deeper. As winters warm, diet shifts to alternate prey or different habitats in order to avoid interspecific competition could therefore be more probable in large lakes. Such systems, where adaptive capacity is high, could be less sensitive to biodiversity loss under warmer winters.

Cases in which interspecific competition during winter was strong (i.e., cold adapted species exclude warm addapted species) narrowed the region of coexistence (Fig. 6C, D). Reducing the duration of winter in these cases easily drives the winter-adapted species to extinction, meaning winter-adapted species depend on winter periods for maintaining coexistence (Fig. 6C, D). In a simplified sense, the theory therefore suggests that the role of time and space in mediating coexistence may be context-dependent. More specifically, when an ecosystem is spatially constrained with heightened interactions within a trophic level (e.g., small lakes sensu McCann et al. 2005), one may reasonably expect that temporal trade-offs play an increasingly large role in mediating coexistence. Given this, we may predict that winter (and niche divergence through time) could play an increasingly large role in spatially constrained ecosystems for competing mobile species (e.g., top predators in small lakes and islands that overlap significantly in space). If so, the global warming implications may be dire for predator diversity in small temperate lakes. Future work is therefore warranted to continue developing 
new competition theory to understand when temporal vs. spatial coexistence mechanisms may be expected to operate, even within the same ecosystem (Chesson 1985, 1994, 2020).

Winter can be bad or good for fish growth and still impact coexistence

The qualitative outcomes of the four cases were not dependent on whether the dynamics were synchronized or asynchronized between the two species (for an example of these dynamics see SI S4, Fig. S5). Coexistence is therefore possible between species exhibiting a trade-off between maximizing open water growth and winter activity, regardless of whether winter is 'bad' or 'good' for the population growth of the winter-adapted species. As long as the more winter-adapted species is more buffered from negative effects than the summer-adapted species, the two species can coexist. Relative non-linearity (i.e., a fluctuation-dependent coexistence mechanism) also has this feature of certain contexts (e.g., low resource densities) being universally bad for coexisting species (Armstrong and McGehee 1980). Of course, losses during winter must be recovered during other seasons or species will face extirpation, but our theory hints that winter need not be a time of positive growth to promote coexistence. On the contrary, winter might still be 'bad' for individual and population growth but 'good' for biodiversity as long as species respond differently to environmental variation.

\section{Future work}

Northern temperate regions currently have stable temperatures under ice, ensuring predictable metabolic costs for fishes (Garvey et al. 2011) and setting up the conditions for divergent behavioral strategies (i.e., winter active vs. winter inactive; Shuter et al. 2012). The potential for climate change to converge life history and behavioral strategies in ways that intensify competition and threaten biodiversity is receiving increasing attention (Lancaster et al. 2017). 
Overwinter mortality directly affects fish population structure (Biro et al. 2004; Hurst 2007; Rennie et al. 2019) and shorter, weaker winters could change the competitive landscape by allowing more individuals within a population to survive (Shuter and Post 1990). Shorter or intermittent ice-cover due to warming could also increase the activity of species that otherwise rely on inactivity and energy conservation (e.g., Fullerton et al. 2010), simultaneously reducing the competitive advantage of cold-water species during this period. Species coexistence could further be threatened by increased stochastic environmental variation also expected under a changing climate (Gravel et al. 2011). From an energetic standpoint, warmer, more variable temperatures will be more demanding on ectotherms (Williams et al. 2018). Energy losses over winter have direct effects on the performance and reproduction of fish in the growing season (Hurst 2007). Some evidence has already linked shorter winters with reduced reproductive success of a spring spawning, cool water fish (Farmer et al. 2015). Warmer temperatures could also indirectly affect the ability of fishes to acquire resources necessary for growth and reproduction by altering the production of essential biomolecules at the base of the food web (Colombo et al. 2019). On the other hand, warmer winters might benefit the growth of all fishes if the increase in metabolic demand for resources is met (Brodersen et al. 2011) and, at least temporarily, increase species richness through regional shifts in the species pool (Lancaster et al. 2017). This will not necessarily impinge on coexistence, as long as each species still has its opportunity to succeed under the new conditions of longer growing seasons and warmer temperatures (Lancaster et al. 2017).

Predicting how regional changes in climate conditions will balance with local level shifts in species interactions to ultimately influence species biodiversity is a complex task. Whether northern temperate lakes will eventually lose cold-adapted species and gradually transition into 
southern temperate lake communities under climate change remains to be seen. We advocate for more directed theoretical and empirical work that considers how species behavior, growth, and reproduction change through seasons and years, including during ice-covered winters, in ways that ultimately influence biotic interactions.

A major challenge of such efforts is measuring competition in the field. However, empirical studies can apply a range of tools for mapping how species interactions change seasonally and from year to year (e.g., across years with short and long winters). Acoustic telemetry to measure the 3D movements and activity of fish in the wild is particularly promising (Cruz-Font et al. 2019), especially when coupled with repeated sampling to obtain stomach contents or tissue for dietary analysis (e.g., via stable isotope or fatty acids; Guzzo et al. 2017). Studies have also successfully used netting to capture information about species spatial distributions and overlap through time (Helland et al. 2011). Combined with experimental manipulations of species and resource densities, changes in the strength of competition can be measured between species pairs across changing conditions (including during simulated winter conditions; Hellend et al. 2011).

Winter could also have far-reaching consequences that operate through carry-over effects in other seasons. Species should adaptively anticipate winter's onset and behave accordingly in the spring, summer, and fall. This includes foraging to ensure sufficient resources are acquired for successful spawning and overwinter survival (Plumb et al. 2014). How successful this foraging is could then influence behaviors and survival during winter. Fall spawning fish that have depleted more of their energy reserves immediately before winter, for example, might be forced to forage more than a spring spawning fish that accumulates surplus energy reserves at this time (Shuter et al. 2012). The ability of a warm-water fish to accumulate energy prior to 
winter and to locate suitable habitat and conserve energy during winter could dictate its level of winter activity (Bystrom et al. 2006). A thorough consideration of how winter shapes ecological processes should therefore include connections across seasons.

Finally, spatial sampling across different lakes is also necessary to explore the context dependency of winter on ecological processes. Even though sampling the same lake over time may be the best option for quantifying the local effects of winter duration on a system, having a range of lakes sampled through time would allow one to uncover trends in species behavior and interactions across a gradient of lake conditions. We expect lake size and food web structure, including the presence of high- vs. low-quality prey, to be key mediators of how winter influences fish activity, growth, and interactions with competitors. Only by sampling through time across a gradient of lake size, production and food web structure can we begin to understand how local context shapes species responses to winter. Careful attention should be taken in designing such multi-lake studies because in addition to winter duration, a host of other variables (e.g., water clarity, harvest intensity) can differ among lakes that can impact species behavior and interactions.

We have also stressed the role of competition for coexistence within a trophic guild, due to our focus on top predatory fishes. But seasonal diet switches by these generalist top predators also have important consequences for coexistence within the prey guild (Chesson 2018). For example, flexible diet switches of predators away from declining or inaccessible prey, or suppressed winter activity by a predator, during certain seasons could be important for allowing low density prey to recover, stabilizing whole food webs (McMeans et al. 2015). A general framework for how seasonality and harsh winters influence biotic interactions should include 
individuals, species, and interactions within the community and the larger food web (McMeans et al. 2016; Williams et al. 2018).

A greater focus on seasonality that includes winter periods is warranted. Human activities are broadly homogenizing ecosystems, undermining the heterogeneity that underlies biodiversity. This homogenization is apparent in space (e.g., landscapes transformed for agriculture) and in ecological communities (e.g., the redistribution of species). The climatedriven loss of ice-covered periods on lakes could similarly be viewed as a type of homogenization in time. Weakened winters will make more of the year warmer, brighter, and ice-free, similar to open water periods. If diversity is generated and maintained by species filling niches in time, as the environment fluctuates, homogenization in time could have similar negative effects for biodiversity as homogenization in space (Sabzo et al. 2016). Understanding and predicting the outcomes of altered seasonal conditions demands a more widespread consideration of how temporal variation broadly, and historically understudied winter periods specifically, shape ecological processes that ultimately influence biodiversity maintenance.

\section{Conclusions}

Temporal variation and periodicity are ubiquitous in nature. Temperate and Arctic latitudes are characterized by seasonal cycles with distinct periods of winter. Here, we have argued for a perspective that emphasizes the roles of seasonal variation and winter-mediated species coexistence. Empirical data from northern temperate lakes suggests that competing fish diverge in their activity and performance during low light, oxygen, or resource conditions that could occur under ice covered winter periods. New theory developed here further argues that: 1) the duration of winter could be critically important for facilitating coexistence in some instances, and 
2) winter need not be 'good' for the growth of a winter-adapted species to promote their coexistence. Future work is tasked with exploring how the environmental context, including lake size, productivity, community, and food web structure (e.g., presence of particular prey, competitors and predators) governs the role of winter for shaping fish behavior, growth, and biotic interactions. We suggest the following predictions to guide future work:

1. Biotic interactions change through time. Coexisting species diverge in their response to seasonal variation. Species can select for different habitats or resources, or vary in their activity and competitive ability, during different seasons. Differential responses and species divergence through time could weaken interspecific competition relative to intraspecific competition and promote coexistence.

2. Other seasons place stress on fish (e.g., summer can pose thermal or oxidative stress), but species diverge most strongly in their activity rates during winter. Some species are expected to be more successful foragers and competitors under the unique conditions of dark, cold, low oxygen, or low resource winter conditions than others. Fluctuation-dependent coexistence via temporal niche divergence could therefore arise most strongly during and around winter periods.

3. Trade-offs exist between performance in open water and winter. Species with a higher capacity for growth in warm or bright periods are less successful during winter periods and vice versa. Other potential trade-offs include thermal breadth and thermal preference (Fig. 2B), thermal breadth and maximum performance at optimal temperatures (Kingsolver 2009) and between maximum growth capacity and tolerance to harsh conditions (Angert et al. 2011).

4. The strength of competition and the extent of niche partitioning varies through time (between seasons and years) and space (between lakes), such that: 
a. Reduced availability or accessibility of resources occurs during winter and should amplify intra- and interspecific competition compared to more productive summer months.

b. The strength of intra- and interspecific competition should be highest in small lakes and weakest in large lakes.

c. However, interspecific competition could be readily dampened by resource or habitat partitioning or divergence of activity rates between species in a given season.

d. Warmer winters are predicted to have the largest negative effects on biodiversity in small lakes. In such lakes, where the capacity for spatial resource partitioning is low, shortening winter periods could increase convergence and synchrony in annual activity patterns and amplify interspecific competition.

5. The importance of niche divergence in time vs. space in mediating coexistence is context dependent. Divergence through time could be most important, generally, in low productivity, small, or highly spatially homogenized ecosystems.

6. Alternatively, if species niche overlap does not respond to winter duration, then winter might be predicted to have minimal effects on biodiversity. If winter causes species to converge in their habitat use or activity level, then long winters might even have a negative effect on biodiversity. In such cases, shorter winters might have little or even positive effects on biodiversity.

\section{Acknowledgements}


The authors graciously thank P. Chesson and two anonymous reviewers for helpful comments on an earlier version of this article. BCM and MDR thank NSERC Discovery Grants for funding and the Canada Research Chair program to MDR. Northern research was supported by Fisheries \& Oceans Canada and DeBeers Canada to PJB.

\section{Author contributions}

$\mathrm{BCM}$ conceived the idea for the manuscript and wrote the first draft. KSM conceived and developed the theory with CB. MMG, TB, PB, TF, HG, TM, MDR, MSR and BS contributed data and figures and all authors contributed to writing and editing and the manuscript. 


\section{Box 1. Winter mediates biotic interactions: an empirical case study between thermal guilds}

As an example of how winter can mediate the interaction between predator species with differing thermal preferences in a way that could promote their coexistence, we looked at smallmouth bass (warm-water guild) and lake trout (cold-water guild) in Lake of the Two Rivers, Ontario, Canada (45 34' 42.6” N, 78²9’ 0.4” W, 274 ha, 38 m maximum depth). Both species are generalist predators that consume invertebrates and fish. Although lake trout are restricted to cold, offshore waters during summer and smallmouth bass occupy warm, inshore zones, lake trout make inshore forays to consume littoral invertebrates and fish (Guzzo et al. 2017; Tunney et al. 2012). Inshore foraging is especially important for lake trout production in small lakes that lack an offshore forage fish, like our study lake (i.e., where lake trout must move to littoral zones to feed on fish; Vander Zanden and Rasmussen 1996). When present, invasive smallmouth bass have been shown to reduce lake trout reliance on littoral prey (Vander Zanden et al. 1999), suggesting lake trout likely experience negative interspecific competitive effects from smallmouth bass.

Acoustic telemetry data (explained in SI S1) were used to calculate both spatial positioning of each species (akin to habitat partitioning) and mean activity rates (akin to temporal niche partitioning). The combined depth and positional data demonstrated clear spatial separation of the two species in summer. Smallmouth bass occupied warm, inshore and shallow waters and lake trout occupied offshore, cooler water below the thermocline (Fig. 3A, B, C). These tendencies are consistent with a role of temperature-driven, resource partitioning as an important coexistence mechanism for these species (Tonn and Magnuson 1987). As the lake turns over and surface waters fall below $15^{\circ} \mathrm{C}$ in the fall, however, lake trout ascend in the water column towards the surface and move into inshore, littoral habitats (Fig. 3B, C). During winter, lake trout 
remain inshore and occupy shallower water than smallmouth bass throughout the winter and early spring (Fig. 3A, B).

Despite the increase in spatial overlap between these two species during fall turnover and winter ice cover, they appear to behaviorally differentiate in time. The activity rate data uncovered that smallmouth bass substantially reduced their activity levels during winter, but lake trout remained active in summer and winter (with activity spikes in the fall likely associated with fall spawning; Fig. 3D). Previous findings also demonstrate that warm water fish reduce their activity and foraging under ice (although some swimming and foraging is still possible; Suski et al. 2007), and that cold water salmonids can sustain similar activity rates between summer and winter (Blanchfield et al. 2009). Resources could potentially be limited during winter, making competition likely, because piscivorous fish are able to consumptively drawdown prey during the open water months (e.g. Vander Zanden et al. 1999). Reduced light could further decrease resource abundance (Hampton et al. 2016) or limit the ability of visually-oriented fish to access resources under ice cover (Blanchfield et al. 2009; Varpe et al. 2015). However, winter-active species could experience weaker interspecific competition during winter, as their warm-adapted competitors become inactive or less successful foragers and competitors.

Seasonal patterns in activity appear to translate to inter-annual patterns in individual growth for these two species. Although growth data were not available for both lake trout and smallmouth bass in our study lake, back-calculated individual growth data from Lake Opeongo (a larger, nearby lake that contains an offshore forage fish) suggest that lake trout are better able to maintain their biomass during years with long winters compared to smallmouth bass (Fig. 4A, B). Although lake trout growth rates vary widely from lake to lake (e.g., depending on the presence or absence of an offshore forage fish; Fig. 4C), lake trout are expected to be more 
active and capable of feeding than smallmouth bass during winter based on bioenergetic considerations (see SI S3). More data are needed to establish the context dependencies of how winter duration influences relative growth rates between competing species. However, years with longer winters would be expected to reduce the time for resource acquisition and investment into growth and reproduction for the warm-water smallmouth bass to a greater degree than cold-water lake trout (Christie \& Regier 1988; Giacomini \& Shuter 2013; King et al. 1999). Different conditions therefore appear to favor different species, and thermal performance trade-offs could set the stage for multiple potential coexistence mechanisms, including niche partitioning in space and time (Chesson 2020). 


\section{Box 2: Empirical case study of winter habitat use and activity rates within a thermal guild}

To evaluate how species that share thermal preferences differentiate in winter, we examined lake trout and burbot using available acoustic telemetry data from Alexie Lake $\left(62^{\circ} 40^{\prime} 36.59^{\prime \prime} \mathrm{N}, 114^{\circ}\right.$ 4'22.76"W), located approximately $30 \mathrm{~km}$ north east of Yellowknife, Northwest Territories (NT), Canada. Alexie Lake is a medium-sized (402 ha, maximum depth $32 \mathrm{~m}$ ) oligotrophic lake that thermally stratifies in the summer and experiences approximately 6 months of ice cover annually. Lake trout and burbot both belong to the cold water thermal guild and are piscivores, but separate spatially in their habitat use (Guzzo et al. 2016). Acoustic telemetry data (see SI S1 for detail) indicate that lake trout are pelagic, spending the majority of their time around $10 \mathrm{~m}$ depth, while burbot are benthic and spend time on the bottom in shallower water (Fig. 5A, C). Seasonal patterns in mean daily activity rates broadly overlap because both species exhibit their minimum activity rates in the summer (Fig. 5D), when they both occupy deeper water (Fig. 5C). However, the timing of maximum activity rates clearly diverge, likely reflecting differences in their life history. Lake trout peak in their activity in the fall while burbot peak in the winter (Fig. 5D). While lake trout do remain active in winter, because winter activity rates stay above minimum values observed in summer, activity rates slowly decline as the winter progresses in this sub-Arctic lake (from December to March; Fig. 5D). This is, however, not the case for burbot, which spawn in the winter under the ice (Cott et al. 2013). Burbot remain as active in mid and late winter as early winter, and actually increase their activity through winter as their spawn time approaches (Fig. 5C), despite reduced light availability (Fig. 5B).

Lake trout and burbot are additionally known to diverge in the daily timing of their foraging. Lake trout feed most during the day or crepuscular periods, and burbot during the night (Guzzo et al. 2016, Cott et al. 2015). While this would prevent interference competition from 
occurring, exploitative competition is still possible if one species is suppressing the resources available to the other species. Lake trout are known to be visual predators (Blanchfield et al. 2009; Vogel \& Beauchamp 1999). Alternatively, the photophobic behavior of burbot, which successfully and exclusively forages in the dark (Cott et al. 2015), could suggest they are more effective predators and competitors during the parts of winter when light is most limited by both reduced photoperiod and greatest snow and ice build-up (in our case, mid-winter; Fig. 5B). We do not have prey capture rates or winter diet information to explore this idea further. However, a greater foraging advantage provided by dark winters to burbot could explain their sustained activity rates during this part of the season compared to lake trout (Fig. 5B, D). Trade-offs between successful foraging in bright vs. dark parts of the year could therefore be operating to favor different species at different times (Helland et al. 2011; Vogel \& Beauchamp 1999), similar to the thermally driven trade-off that seems to favor warm-adapted species in summer and cold-adapted species in winter (Box 1). Here, more visual species could be favored by brighter seasons (fall, early winter and spring) relative to species that forage better in dark, late winter conditions. Again, each species having their time of greatest success is the key to fluctuation-dependent coexistence. This example suggests that species can partition both among but also within a given season (i.e., early vs. mid-winter). 


\section{Box 3. Theoretical consideration of how winter influences coexistence}

We used the classical 2 species Lotka-Volterra competition models, but explicitly consider dynamics in two discrete seasons, open water and winter. Open water $\left(f_{S}\right)$ and winter $\left(f_{W}\right)$ are modelled as fractions summing to $1\left(f_{S}+f_{W}=1\right)$ and each species is modelled with seasonspecific parameter combinations. In this way models are integrated over numerous years but within each year they sequentially follow first open water then winter parameters corresponding to the given seasonal fractions within the year. The seasonal fractions allow us to change the proportion of the year that is winter (e.g., reduce $f_{W}$ to mimic warming). The open water and winter models for species $\mathrm{X}_{1}$ and $\mathrm{X}_{2}$ are as follows:

$$
\frac{d X_{i}}{d t}=r_{i, k} X_{i}\left(1-\frac{\left(X_{i}+\alpha_{i j, k} X_{j}\right)}{K_{i, k}}\right)
$$

where $i$ and $j$ are the competing species, $r_{i, k}$ is the intrinsic rate of population growth for species $i$ in season $k$ (i.e., open water or winter), $K_{i, k}$ is the carrying capacity (a surrogate for productivity) for species $i$ in season $k$, and $\alpha_{i j, k}$, the competition coefficient, is the competitive effect of species $j$ on $i$ in season $k$ (see Table 1 for parameters). Note that many competition models nondimensionalize the parameters such that interspecific competition is scaled to carrying capacity $\left(\alpha_{i j, k} / K_{i}\right)$, although parameterizing the model with absolute competition coefficients ( $\alpha_{i i}$ and $\left.\alpha_{i j}\right)$ more clearly indicates the coexistence outcome (Chesson 2000). In our model, we chose to employ classical Lotka-Volterra model parameters because we felt they make our biological assumptions map more clearly to our empirical arguments. As an example, we wanted to alter carrying capacity explicitly $\left(K_{i}\right)$ in order to match our empirical observations that the accessibility of resources in a given habitat changes seasonally (Guzzo et al. 2017). In our case, 
competition can change indirectly as a result of $K_{i}$ (lower $K_{i}$ reduces resource availability and effectively increases inter- and intraspecific competition) or directly by changing the $\alpha_{i j}$.

With respect to the seasonal environment, we make the following two assumptions:

1. Winter is less productive than open water (i.e., $K_{i, S}>K_{i, W}$ )

2. Maximal growth rates are smaller in winter than open water (i.e., $r_{i, S}>r_{i, W}$ )

For the two species, we assume the following trade-offs in the parameters:

1. Species 1 has higher growth rates in open water $\left(r_{1, S}>r_{2, S}\right)$ and lower growth rates in winter $\left(r_{2, W}>r_{1, W}\right)$, compared to species 2 .

2. Species 2 growth rate remains more constant throughout the year.

3. Species 2 is a stronger interspecific competitor in winter $\left(\alpha_{12, W}>\alpha_{21, W}\right)$, but Species 1 is a stronger interspecific competitor in open water $\left(\alpha_{21, S}>\alpha_{12, S}\right)$.

With the above assumptions, we then consider four different competition cases where we alter the strength of interspecific competition to explore how winter length $\left(f_{W}\right)$ influences coexistence under different, empirically motivated scenarios of strong vs. weak competition in each season (Table 1). We explored the qualitative outcomes for coexistence under both synchronized and asynchronized species dynamics (see SI S4).

Case 1. Competition is relatively weak in both seasons (Weak-weak, Fig. 6A). Here, weak-weak refers to competition coefficients that yield coexistence conditions in both open water and winter. Weak interspecific competition could arise in large lakes where species spatially separate 
in their resource use, or when species diverge in their winter activity rates (one is active and one is inactive).

Case 2. Competition strengthens in summer but remains weak in winter (Strong-weak, Fig. 6B). Here, strong-weak refers to competition coefficients that yield competitive exclusion conditions in summer and coexistence in winter. Interspecific competition could strengthen in summer (relative to case 1) in lower productivity or smaller lakes. Winter competition could remain relatively weak for the reasons listed above in case 1.

Case 3. Competition remains weak in summer but strengthens in winter (Weak-strong, Fig. 6C). Weak-strong refers to competition coefficients that yield coexistence conditions in summer and exclusion in winter. Here, species could partition resources in summer that weakens interspecific competition, as in case 1 above. During winter, however, species niche overlap could increase in cases where both species are actively foraging during winter, amplifying interspecific competition compared to case 1.

Case 4. Strong competition in both summer and winter (Strong-strong, Fig. 6D). Strong-strong refers to competition coefficients that yield exclusion conditions in both summer and winter. In smaller lakes with less ice cover, we imagine that interspecific competition could be strengthened relative to case 1 in both summer (e.g. due to increased resource overlap) and winter (e.g. due to greater synchrony in annual activity patterns). 
Table 1. Parameter values used to (1) generate trade-offs between a warm adapted and coldadapted species, and (2) to create strong and weak competition scenarios during two seasons. Strong and weak scenarios relate to competitive exclusion and coexistence, respectively.

\begin{tabular}{|c|c|c|c|c|c|c|c|}
\hline \multicolumn{4}{|l|}{ Summer } & \multicolumn{4}{|l|}{ Winter } \\
\hline Strong & $\mathrm{a}_{12}=0.5$ & Weak & $\mathrm{a}_{12}=0.5$ & Strong & $\mathrm{a}_{12}=1.3$ & Weak & $\mathrm{a}_{12}=1.1$ \\
\hline & $\mathrm{a}_{21}=0.8$ & & $\mathrm{a}_{21}=0.8$ & & $\mathrm{a}_{21}=1.1$ & & $\mathrm{a}_{21}=0.3$ \\
\hline & $\mathrm{r}_{1}=1.7$ & & $\mathrm{r}_{1}=1.7$ & & $\mathrm{r}_{1}=0.3$ & & $\mathrm{r}_{1}=0.3$ \\
\hline & $\mathrm{r}_{2}=1.2$ & & $\mathrm{r}_{2}=1.2$ & & $\mathrm{r}_{2}=1.0$ & & $\mathrm{r}_{2}=1.0$ \\
\hline & $\mathrm{K}_{1}=2.0$ & & $\mathrm{~K}_{1}=2.5$ & & $\mathrm{~K}_{1}=0.25$ & & $\mathrm{~K}_{1}=0.9$ \\
\hline & $\mathrm{K}_{2}=1.5$ & & $\mathrm{~K}_{2}=2.4$ & & $\mathrm{~K}_{2}=0.7$ & & $\mathrm{~K}_{2}=0.7$ \\
\hline & $\mathrm{K}_{1}>\mathrm{K}_{2} / \mathrm{a}_{21}$ & & $\mathrm{~K}_{1}<\mathrm{K}_{2} / \mathrm{a}_{21}$ & & $\mathrm{~K}_{1}<\mathrm{K}_{2} / \mathrm{a}_{21}$ & & $\mathrm{~K}_{1}<\mathrm{K}_{2} / \mathrm{a}_{21}$ \\
\hline & $\mathrm{K}_{2}<\mathrm{K}_{1} / \mathrm{a}_{12}$ & & $\mathrm{~K}_{2}<\mathrm{K}_{1} / \mathrm{a}_{12}$ & & $\mathrm{~K}_{2}>\mathrm{K}_{1} / \mathrm{a}_{12}$ & & $\mathrm{~K}_{2}<\mathrm{K}_{1} / \mathrm{a}_{12}$ \\
\hline & sp. 1 wins & & coexist & & sp. 2 wins & & coexist \\
\hline
\end{tabular}




\section{References}

Adler, P. B., HilleRisLambers, J. \& Levine, J. M. (2007). A niche for neutrality. Ecol.Lett., 10, 95-104.

Adler, P. B., HilleRisLambers, J., Kyriakidis, P. C., Guan, Q. \& Levine, J. M. (2006). Climate variability has a stabilizing effect on the coexistence of prairie grasses.

Proc.Natl.Acad.Sci.U.S.A., 103, 12793-12798.

Amundsen, P. \& Knudsen, R. (2009). Winter ecology of arctic charr (Salvelinus alpinus) and Brown Trout (Salmo trutta) in a subarctic lake, norway. Aquat.Ecol., 43, 765-775.

Angert, A. L., Huxman, T. E., Chesson, P. \& Venable, D. L. (2009). Functional tradeoffs determine species coexistence via the storage effect. Proc.Natl.Acad.Sci.U.S.A., 106, 1164111645.

Armstrong, R. A. \& McGehee, R. (1980). Competitive exclusion. Am.Nat., 115, 151-170.

Bartley, T. J., McCann, K. S., Bieg, C., Cazelles, K., Granados, M., Guzzo, M. M., MacDougall, A. S., Tunney, T. D., \& McMeans, B. C. (2019). Food web rewiring in a changing world. Nature Eco Evol 3, 345-354.

Biro, P., Morton, A., Post, J., \& Parkinson, E. (2004) Overwinter lipid depletion and mortality of age-0 rainbow trout (Oncorhynchus mykiss). Can. J. Fish. Aquat. Sci. 61: 1513-1519.

Blanchfield, P. J., Tate, L. S., Plumb, J. M., Acolas, M. \& Beaty, K. G. (2009). Seasonal habitat selection by Lake Trout (Salvelinus namaycush) in a small Canadian shield lake: Constraints imposed by winter conditions. Aquat.Ecol., 43, 777-787.

Brodersen, J., Rodriquez-Gil, J. L., Jonsson, M., Hansson, L-A., Bronmark, C., Anders Nilsson, P., Nicolle, A., \& Berglund, O. (2011). Temperature and resource availability may interactively affect over-wintering success of juvenile fish in a changing climate. Plos One, 6 (10) e24022

Byström, P., Andersson, J., Kiessling, A. \& Eriksson, L. (2006). Size and temperature dependent foraging capacities and metabolism: Consequences for winter starvation mortality in fish. Oikos, $115,43-52$.

Caceres, C. E. (1997). Temporal variation, dormancy, and coexistence: A field test of the storage effect. Proc.Natl.Acad.Sci.U.S.A., 94, 9171-9175.

Casselman, J. M., Brown, D. M., Hoyle, J. A., \& Eckert, T. H. (2002) Effects of temperature, global extremes and climate warming on year-class production of warmwater, coolwater and coldwater fishes. In: McGinn NA (ed) Fisheries in a changing climate. American Fisheries Society, Bethesda, pp 39-60

Chase, J. M. \& Leibold, M. A. (2002). Spatial scale dictates the productivity-biodiversity relationship. Nature, 416, 427. 
Chesson, P. (2020). Species coexistence, Chapter 2 in K.S. McCann and G. Gellner, eds, Theoretical Ecology: concepts and applications, Oxford University Press

Chesson, P. (2018). Updates on mechanisms of maintenance of species diversity. J.Ecol., 106, 1773-1794.

Chesson, P. (2000). Mechanisms of maintenance of species diversity. Annu. Rev. Ecol. Syst., 31, 343-366.

Chesson, P. (1994). Multispecies competition in variable environments. Theor. Pop. Biol, 45, 227-276.

Chesson, P. \& Huntly, N. (1997). The roles of harsh and fluctuating conditions in the dynamics of ecological communities. Am.Nat., 150, 519-553.

Chesson, P., Huntly, N. J., Roxburgh, S. H., Pantastico-Caldas, M. \& Facelli, J. M. (2012). The Storage Effect: Definition and Tests in Two Plant Communities. In: Temporal dynamics and ecological process (Anonymous . Cambridge University Press, pp. 11-40.

Chesson, P. L. (1985). Coexistence of competitors in spatially and temporally varying environments: A look at the combined effects of different sorts of variability. Theor.Popul.Biol., 28, 263-287.

Christie, G. C. \& Regier, H. A. (1988). Measures of optimal thermal habitat and their relationship to yields for four commercial fish species. Can.J.Fish.Aquat.Sci., 45, 301-314.

Clark, J. S. (2010). Individuals and the variation needed for high species diversity in forest trees. Science 327(5969), 1129-1132.

Colombo, S.M., Rodgers, T.F.M., Diamond, M.L. et al. Ambio (2019). https://doi.org/10.1007/s13280-019-01234-6

Cott, P. A., Johnston, T. A., \& Gunn, J. M. (2013) Sexual dimorphism in an under-ice spawning fish: the Burbot (Lota lota). Can J Zool 91: 732-740.

Cott, P. A., Guzzo, M. M., Chapelsky, A. J., Milne, S. W., \& Blanchfield, P. J. (2015) Diel bank migration of Burbot (Lota lota). Hydrobiol. 757(1), 3-20.

Cruz-Font, L., Shuter, B. J., Blanchfield, P. J., Minns, C. K. \& Rennie, M. D. (2019). Life at the top: Lake ecotype influences the foraging pattern, metabolic costs and life history of an apex fish predator. J.Anim.Ecol., 88, 702-716.

Cunjak, R. A., Curry, A. \& Power, G. (1987). Seasonal energy budget of Brook Trout in streams: Implications of a possible deficit in early winter. Trans.Am.Fish.Soc., 116, 817-828.

Descamps-Julien, B. \& Gonzalez, A. (2005). Stable coexistence in a fluctuating environment: An experimental demonstration. Ecology, 86, 2815-2824. 
Diez, M. J., Cabreira, A. G., Madirolas, A., De Nascimento, J. M., Scioscia, G., Schiavini, A. \& Lovrich, G. A. (2018). Winter is cool: Spatio-temporal patterns of the Squat Lobster Munida gregaria and the Fuegian Sprat Sprattus fuegensis in a sub-antarctic estuarine environment. Polar Biol., 41, 2591-2605.

Ellner, S. P., Snyder, R. E. \& Adler, P. B. (2016). How to quantify the temporal storage effect using simulations instead of math. Ecol.Lett., 19, 1333-1342.

Eloranta, A., Knudsen, R. \& Amundsen, P. (2013). Niche segregation of coexisting Arctic Charr (Salvelinus alpinus) and Brown Trout (Salmo trutta) constrains food web coupling in subarctic lakes. Freshwat.Biol., 58, 207-221.

Farmer, T. M., Marschall, E. A., Dabrowski, K., \& Ludsin, S. A. (2015) Short winters threaten temperate fish populations. Nat Comm 6, 7724.

French, W. E., Vondracek, B., Ferrington Jr, L. C., Finlay, J. C. \& Dieterman, D. J. (2014). Winter feeding, growth and condition of brown trout Salmo trutta in a groundwater-dominated stream. J.Freshwat.Ecol., 29, 187-200.

Fry, F. E. J. 1947. Effects ofthe environment on animal activity. Univ. Toronto Stud. Biol. Ser. 55, Publ. Ontario Fish. Res. Lab. 68:1-62.

Fullerton, A. H., Garvey, J. E., Wright, R. A. \& Stein, R. A. (2000). Overwinter growth and survival of largemouth bass: Interactions among size, food, origin, and winter severity.

Trans.Am.Fish.Soc., 129, 1-12.

Garvey, J. E., Ostrand, K. G. \& Wahl, D. H. (2004). Energetics, predation, and ration affect sizedependent growth and mortality of fish during winter. Ecology, 85, 2860-2871.

Giacomini, H. C. \& Shuter, B. J. (2013). Adaptive responses of energy storage and fish life histories to climatic gradients. J.Theor.Biol., 339, 100-111.

Gravel, D., Guichard, F., \& Hochberg, M. E. (2011) Species coexistence in a variable world. Eco Lett $14,828-839$.

Guzzo, M. M., Blanchfield, P. J., Chapelsky, A. J., \& P. A. Cott. (2016) Resource partitioning among top-level piscivores in a sub-Arctic lake during thermal stratification. J Great Lakes Res 42, 276-285.

Guzzo, M. M., Blanchfield, P. J. \& Rennie, M. D. (2017). Behavioral responses to annual temperature variation alter the dominant energy pathway, growth, and condition of a cold-water predator. Proc.Natl.Acad.Sci.U.S.A., 114, 9912-9917.

Hart, S. P. \& Marshall, D. J. (2013). Environmental stress, facilitation, competition, and coexistence. Ecology, 94, 2719-2731. 
Hasnain, S. S., M.D. Escobar and B.J. Shuter. (2018). Estimating thermal response metrics for North American freshwater fish using Bayesian phylogenetic regression. Can. J. Fish. Aquat. Sci., 75, 1878-1885.

Hayden, B., Harrod, C. \& Kahilainen, K. K. (2014). Lake morphometry and resource polymorphism determine niche segregation between cool-and cold-water-adapted fish. Ecology, 95, 538-552.

Hayden, B., Harrod, C., Sonninen, E. \& Kahilainen, K. K. (2015). Seasonal depletion of resources intensifies trophic interactions in subarctic freshwater fish communities.

Freshwat.Biol., 60, 1000-1015.

Helland, I. P., Finstad, A. G., Forseth, T., Hesthagen, T. \& Ugedal, O. (2011). Ice-cover effects on competitive interactions between two fish species. J.Anim.Ecol., 80, 539-547.

Hokanson, K. E. F. 1977: Temperature requirements of some percids and adaptations to the seasonal temperature cycle. Journal of the Fisheries Research Board of Canada 34: 1524-1550.

Holbrook, S. J. \& Schmitt, R. J. (1989). Resource overlap, prey dynamics, and the strength of competition. Ecology, 70, 1943-1953.

Holker, F., Volkmann, S., Wolter, C., van Dijk P. L. M. \& Hardewig, I. (2004) Colonization of the freshwater environment by a marine invader: how to cope with warm summer temperatures? Evol Ecol Res 6: 1123-1144.

Humphries, M. M., Studd, E. K., Menzies, A. K. \& Boutin, S. (2017). To everything there is a season: Summer-to-winter food webs and the functional traits of keystone species, 57, 961-976.

Hurst, T. (2007). Causes and consequences of winter mortality in fishes. J.Fish Biol., 71, 315345.

Huston, M. A. (2014). Disturbance, productivity, and species diversity: empiricism vs. logic in ecological theory. Ecology 95(9), 2382-2396.

Hutchinson, G. E. (1961). The paradox of the plankton. Am.Nat., 95, 137-145.

Jeltsch, F., Bonte, D., Pe'er, G., Reineking, B., Leimgruber, P., Balkenhol, N., Schröder, B., Buchmann, C. M., Mueller, T. \& Blaum, N. (2013). Integrating movement ecology with biodiversity research-exploring new avenues to address spatiotemporal biodiversity dynamics, 1 , 6.

Jewson, D. H., Granin, N. G., Zhdanov, A. A. \& Gnatovsky, R. Y. (2009). Effect of snow depth on under-ice irradiance and growth of aulacoseira baicalensis in lake baikal. Aquat.Ecol., 43, 673-679.

King, J., Shuter, B. \& Zimmerman, A. (1999). Empirical links between thermal habitat, fish growth, and climate change. Trans.Am.Fish.Soc., 128, 656-665. 
King, J., Shuter, B. \& Zimmerman, A. (1999). Empirical links between thermal habitat, fish growth, and climate change. Trans.Am.Fish.Soc., 128, 656-665.

Kingsolver, J. G. (2009). The well-temperatured biologist: (american society of naturalists presidential address). Am.Nat., 174, 755-768.

Lancaster, L. T., Morrison, G. \& Fitt, R. N. (2017). Life history trade-offs, the intensity of competition, and coexistence in novel and evolving communities under climate change, 372, 20160046.

Macarthur, R. \& Levins, R. (1964). Competition, habitat selection, and character displacement in a patchy environment. Proc.Natl.Acad.Sci.U.S.A., 51, 1207-1210.

Mackereth, R. W., Noakes, D. L. \& Ridgway, M. S. (1998). Size-Based Variation in Somatic Energy Reserves and Parental Expenditure by Male Smallmouth Bass, Micropterus dolomieu. In: When do fishes become juveniles? (Anonymous . Springer, pp. 263-275.

Magnuson, J. J., Crowder, L. B. \& Medvick, P. A. (1979). Temperature as an ecological resource. Am.Zool., 19, 331-343.

Mariash, H. L., Cusson, M. \& Rautio, M. (2017). Fall composition of storage lipids is associated with the overwintering strategy of daphnia. Lipids, 52, 83-91.

Mathias, A. \& Chesson, P. (2013). Coexistence and evolutionary dynamics mediated by seasonal environmental variation in annual plant communities. Theor.Popul.Biol., 84, 56-71.

McCann, K. S., Rasmussen, J. \& Umbanhowar, J. (2005). The dynamics of spatially coupled food webs. Ecol.Lett., 8, 513-523.

McMeans, B. C., McCann, K. S., Humphries, M., Rooney, N. \& Fisk, A. T. (2015). Food web structure in temporally-forced ecosystems, Trends Ecol. Evol. 30, 662-672.

McMeans, B. C., McCann, K. S., Tunney, T. D., Fisk, A. T., Muir, A. M., Lester, N., Shuter, B. \& Rooney, N. (2016). The adaptive capacity of lake food webs: From individuals to ecosystems. Ecol.Monogr., 86, 4-19.

Mellard, J. P., Audoye, P. \& Loreau, M. (2019). Seasonal patterns in species diversity across biomes. Ecology, 100, e02627.

Micucci, S. M., Garvey, J. E., Wright, R. A. \& Stein, R. A. (2003). Individual growth and foraging responses of age-0 largemouth bass to mixed prey assemblages during winter. Environ.Biol.Fishes, 67, 157-168.

Miller, E. T. \& Klausmeier, C. A. (2017). Evolutionary stability of coexistence due to the storage effect in a two-season model, 10, 91-103. 
Persson, L. (1986). Temperature-induced shift in foraging ability in two fish species, roach (rutilus rutilus) and perch (perca fluviatilis): Implications for coexistence between poikilotherms, 829-839.

Plumb, J. M., Blanchfield, P. J. \& Abrahams, M. V. (2014). A dynamic-bioenergetics model to assess depth selection and reproductive growth by lake trout (Salvelinus namaycush). Oecologia, $175,549-563$.

Pörtner, H. O., Peck, L. \& Somero, G. (2007). Thermal limits and adaptation in marine antarctic ectotherms: An integrative view, 362, 2233-2258.

Rennie, M. D., Kennedy, P. J., Mills, K. H., Rodgers, C. M., Charles, C., Hrenchuk, L. E., Chalanchuk, S., Blanchfield, P. J., Paterson, M. J. \& Podemski, C. L. (2019). Impacts of freshwater aquaculture on fish communities: A whole-ecosystem experimental approach. Freshwat.Biol., 64, 870-885.

Rosindell, J., Hubbell, S. P. \& Etienne, R. S. (2011). The unified neutral theory of biodiversity and biogeography at age ten, 26, 340-348.

Salonen, K., Leppäranta, M., Viljanen, M. \& Gulati, R. (2009). Perspectives in winter limnology: Closing the annual cycle of freezing lakes. Aquat.Ecol., 43, 609-616.

Schoener, T. W. (1982). The controversy over interspecific competition.

Secor, S. M. \& Carey, H. V. (2011). Integrative physiology of fasting, 6, 773-825.

Sharma, S., Blagrave, K., Magnuson, J.J., O’Reilly, C., Oliver, S., Batt, R.D., Magee, M., Straile, D., Weyhenmeyer, G., Winslow, L. and Woolway, R.I. 2019. Widespread loss of lake ice around the Northern Hemisphere in a warming world. Nature Climate Change 9: 227-231.

Shimadzu, H., Dornelas, M., Henderson, P. A. \& Magurran, A. E. (2013). Diversity is maintained by seasonal variation in species abundance, $11,98$.

Shuter, B. \& Post, J. (1990). Climate, population viability, and the zoogeography of temperate fishes. Trans.Am.Fish.Soc., 119, 314-336.

Shuter, B., Finstad, A. G., Helland, L. P., Zwimiller, I. Z., \& Holker, F. (2012). The role of winter phenology in shaping the ecology of freshwater fish and their sensitivities to climate change. Aquat. Sci., 74, 637-657.

Szabó, P. (2016). Ideal free distribution of metabolic activity: Implications of seasonal metabolic-activity patterns on competitive coexistence. Theor.Popul.Biol., 111, 1-8.

Terzhevik, A., Golosov, S., Palshin, N., Mitrokhov, A., Zdorovennov, R., Zdorovennova, G., Kirillin, G., Shipunova, E. \& Zverev, I. (2009). Some features of the thermal and dissolved oxygen structure in boreal, shallow ice-covered lake vendyurskoe, russia. Aquat.Ecol., 43, 617627. 
Tonkin, J. D., Bogan, M. T., Bonada, N., Rios-Touma, B. \& Lytle, D. A. (2017). Seasonality and predictability shape temporal species diversity. Ecology, 98, 1201-1216.

Tonn, W. M. \& Magnuson, J. J. (1982). Patterns in the species composition and richness of fish assemblages in northern wisconsin lakes. Ecology, 63, 1149-1166.

Tredennick, A. T., Adler, P. B. \& Adler, F. R. (2017). The relationship between species richness and ecosystem variability is shaped by the mechanism of coexistence. Ecol.Lett., 20, 958-968.

Tschantz, D. R., Crockett, E. L., Niewiarowski, P. H. \& Londraville, R. L. (2002). Cold acclimation strategy is highly variable among the sunfishes (centrarchidae).

Physiol.Biochem.Zool., 75, 544-556.

Tunney, T. D, McCann, K. S., Lester, P. \& Shuter, B. J. (2012) Food web expansion and contraction in response to changing environmental conditions. Nat Comm, 3:1105.

Vander Zanden, M. J., Casselman, J. M., \& Rasmussen J. B. (1999) Stable isotope evidence for the food web consequences of species invasions in lakes. Nature 401 (40): 464-467.

Vander Zanden, M. J. \& Rasmussen J. B. (1996) A trophic position model of pelagic food webs: impact on contaminant bioaccumulation in lake trout. Ecological Monographs 66 (4): 451-477.

Varpe, O., Daase, M. \& Kristiansen, T. (2015) A fish-eye view on the new Arctic lightscape. ICES J. Mar. Sci. 72(9): 2532-2538.

Vogel, J. L., \& Beauchamp, D. A. (1999) Effects of light, prey size, and turbidity on reaction distances of lake trout (Salvelinus namaycush) to salmonid prey. Can. J. Fish. Aquat. Sci. 56: $1293-1297$.

Watson, B. M., Biagi, C. A., Northrup, S. L., Ohata, M. L., Charles, C., Blanchfield, P. J., Johnston, S. V., Askey, P. J., van Poorten, B. T. \& Devlin, R. H. (2019). Distinct diel and seasonal behaviours in rainbow trout detected by fine-scale acoustic telemetry in a lake environment. Can.J.Fish.Aquat.Sci., 76: 1432-1445.

Werner, I. (2006). Seasonal dynamics, cryo-pelagic interactions and metabolic rates of arctic pack-ice and under-ice fauna-A review. Polarforschung, 75, 1-19.

Weyhenmeyer, G. A., Livingstone, D. M., Meili, M., Jensen, O., Benson, B. \& Magnuson, J. J. (2011). Large geographical differences in the sensitivity of ice-covered lakes and rivers in the northern hemisphere to temperature changes. Global Change Biol., 17, 268-275.

Wiens, J. A. (1977). On competition and variable environments: Populations may experience" ecological crunches" in variable climates, nullifying the assumptions of competition theory and limiting the usefulness of short-term studies of population patterns. Am.Sci., 65, 590-597.

Williams, C. M., Henry, H. A. \& Sinclair, B. J. (2015). Cold truths: How winter drives responses of terrestrial organisms to climate change, 90, 214-235. 
Xiao, X. \& Fussmann, G. F. (2013). Armstrong-mcgehee mechanism revisited: Competitive exclusion and coexistence of nonlinear consumers. J.Theor.Biol., 339, 26-35.

Yuan, C., \& Chesson, P. (2015). The relative importance of relative nonlinearity and the storage effect in the lottery model. Theor. Population Biol., 105, 39-52.

Zepeda, V. \& Martorell, C. (2019). Fluctuation-independent niche differentiation and relative non-linearity drive coexistence in a species-rich grassland. Ecology, e02726. 
Figure 1. A) Northern temperate freshwater fishes vary widely in their responses to winter. Those that are better adapted for winter activity are easily captured during winter sampling operations and tend to have colder thermal preferences (A). Other species can be more challenging to capture under ice cover and tend to have warmer thermal preferences (e.g., bass and other sunfishes; A). Being ectotherms, all fishes should be actively foraging during warmer, brighter open water periods, and have reduced activity rates during winter (B). Fishes with colder thermal preferences (short dash), however, are expected to have a higher capacity for winter activity than species with warmer thermal preferences (long dash; B). Optimal performance under a particular set of conditions implies reduced performance under other conditions and sets up a variety of possible trade-offs (Angert et al. 2009; Kingsolver 2009). For example, a high capacity for activity during warm, bright, open water months is expected to trade-off with a reduced capacity for activity during cold, dark winters (C). Seasonal variation broadly and winter periods specifically could therefore favor different species at different times and promote coexistence of species belonging to multiple thermal guilds (D). In northern temperate lakes, winters are likely long enough to support cold-adapted species but not too long so as to exclude warm-adapted species, making this winter-mediated species coexistence particularly likely (D). 

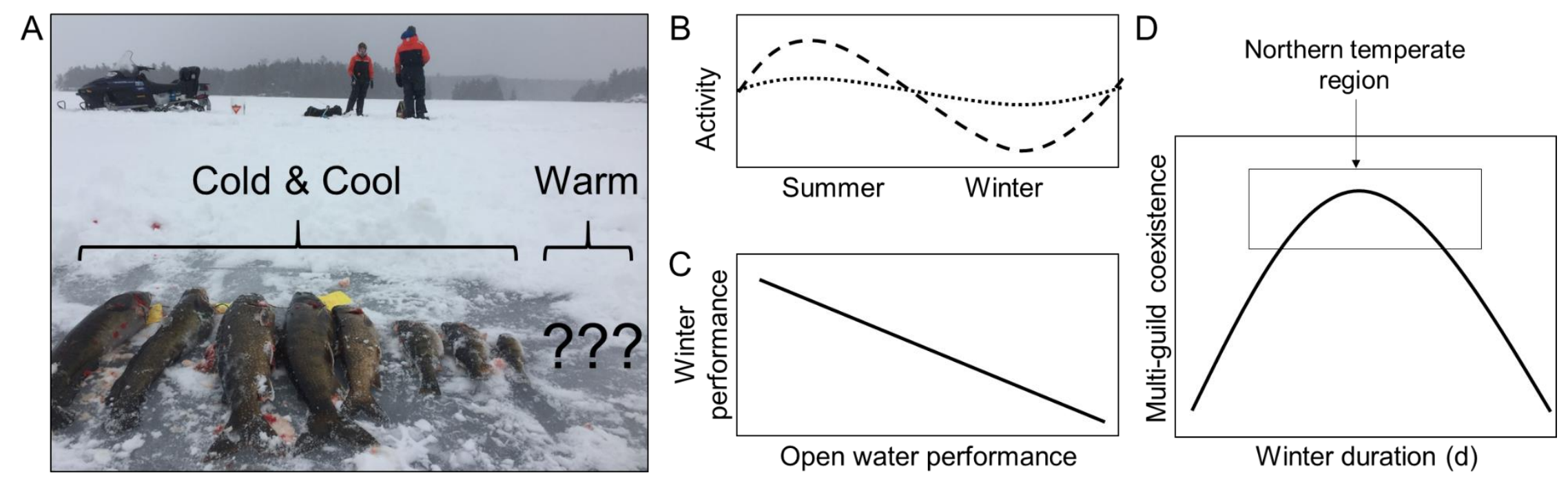
Figure 2. Thermal preferences and thermal niche breadth for Canadian freshwater fishes belonging to three thermal guilds: cold-water, cool-water, and warm-water. A) The continuous distribution of thermal preference (large left point) and upper thermal limit (small right point) for 54 of the most common Canadian freshwater fishes. B) The relationship between thermal preference and thermal breadth (upper thermal limit - thermal preference) for 114 species across the three thermal guilds is negative. These data support thermal performance trade-offs in freshwater fishes. Increased performance at cold temperatures should trade-off with reduced performance at warm temperatures (A) and increased performance at warm temperatures should trade-off with reduced thermal breadth (B). Thermal preference is defined as the temperature that the fish gravitate towards when provided with a broad range of temperatures. Upper thermal limit is the temperature at which $50 \%$ mortality occurs in a population. Data for both panels are from Hasnain et al. (2018).
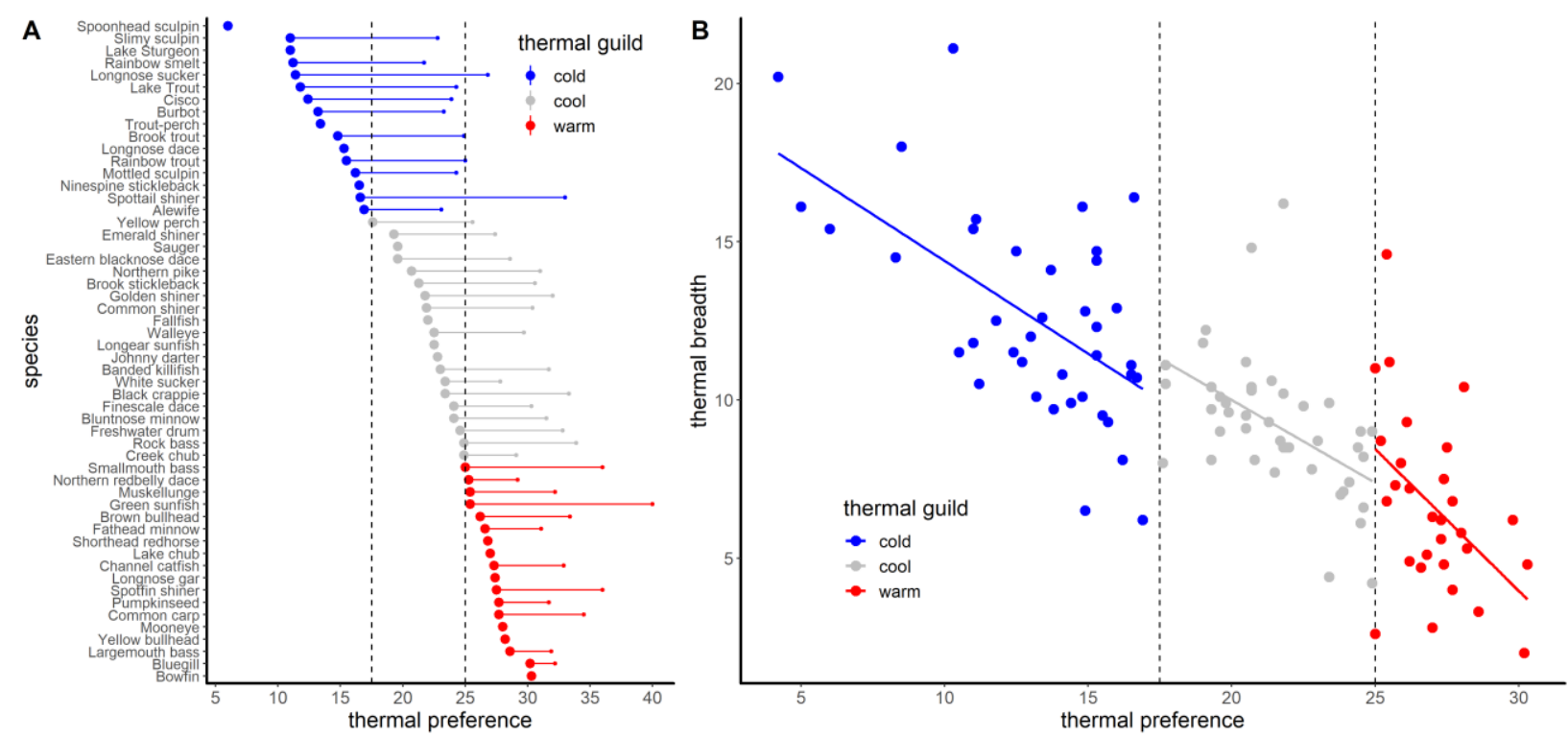
Figure 3. Acoustic telemetry data for lake trout (blue relocations and black triangles) and smallmouth bass (red relocations and white circles) from Lake of the Two Rivers (Ontario, Canada). A) Spatial relocations in summer (top plot; July and August) and winter (bottom plot; January and February). B) Mean daily depth (m) of fish within the water column overlaid over the thermal profile $\left({ }^{\circ} \mathrm{C}\right)$ of the lake across the time series. C) Mean daily bathymetric depth (m) (i.e., depth of water over which fish was positioned). D) Mean daily activity rates $\left(\mathrm{m} \mathrm{min}^{-1}\right)$. For details on the acoustic telemetry data and analyses, see SI S1. 

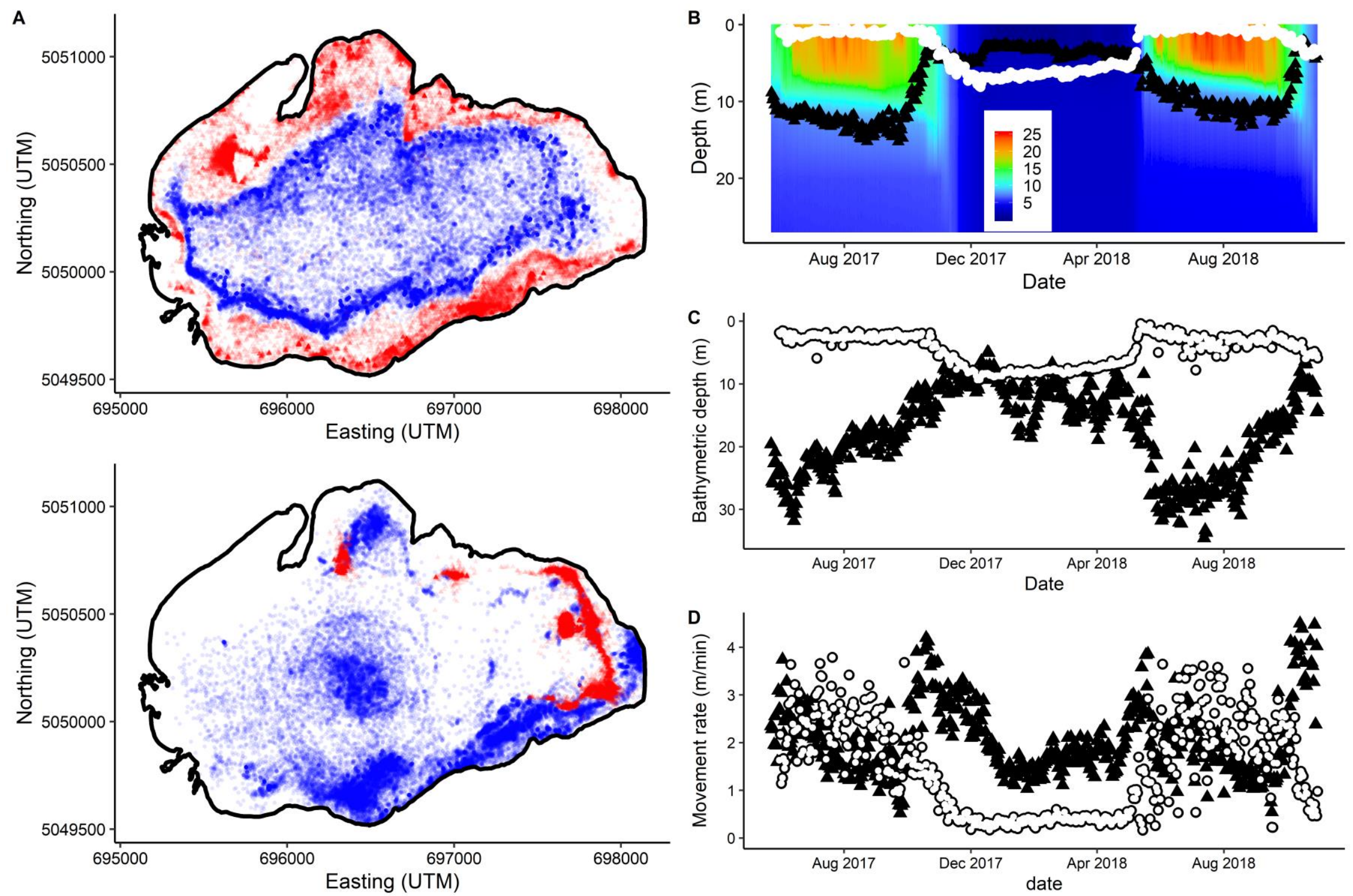
Figure 4. Individual growth of lake trout (A, C) and smallmouth bass (B) in response to interannual changes in winter duration (days). Data from Lake Opeongo, Ontario, Canada (A, B; cm per year relative to maximum length) demonstrate that lake trout are more tolerant to winter duration than smallmouth bass. In smaller lakes lacking an offshore forage fish (Experimental Lakes Area Lake 224 and Lake 373), like our study lake described in Case Study \#1 (Box 1), however, individual lake trout mass (g) declines in years with the longest winters (C). See SI S2 for details on growth calculation and data analysis.
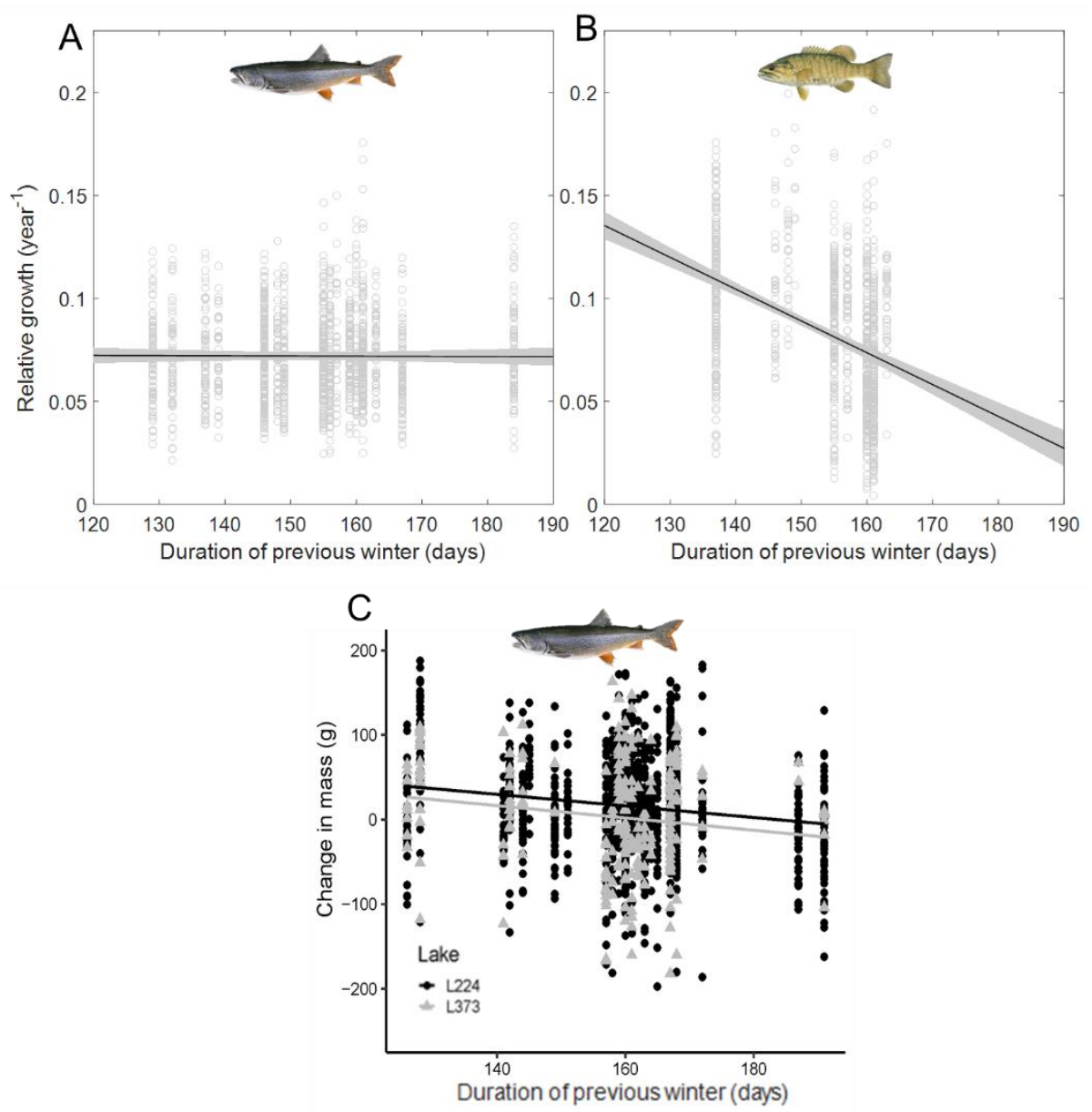
Figure 5. Acoustic telemetry data for lake trout (black triangles) and burbot (white circles) from Alexie Lake (Northwest Territories, Canada). A) Mean daily depth (m) of fish within the water column overlaid over the thermal profile $\left({ }^{\circ} \mathrm{C}\right)$ of the lake across the time series. B) Mean daily light penetration at depth ( $\log _{10}$ Lux) across the time series. C) Mean daily bathymetric depth (m) (i.e., depth of water over which fish was positioned). D) Mean daily activity rates ( $\left.\mathrm{m} \mathrm{min}^{-1}\right)$. For details on the acoustic telemetry data and analyses, see SI S1.
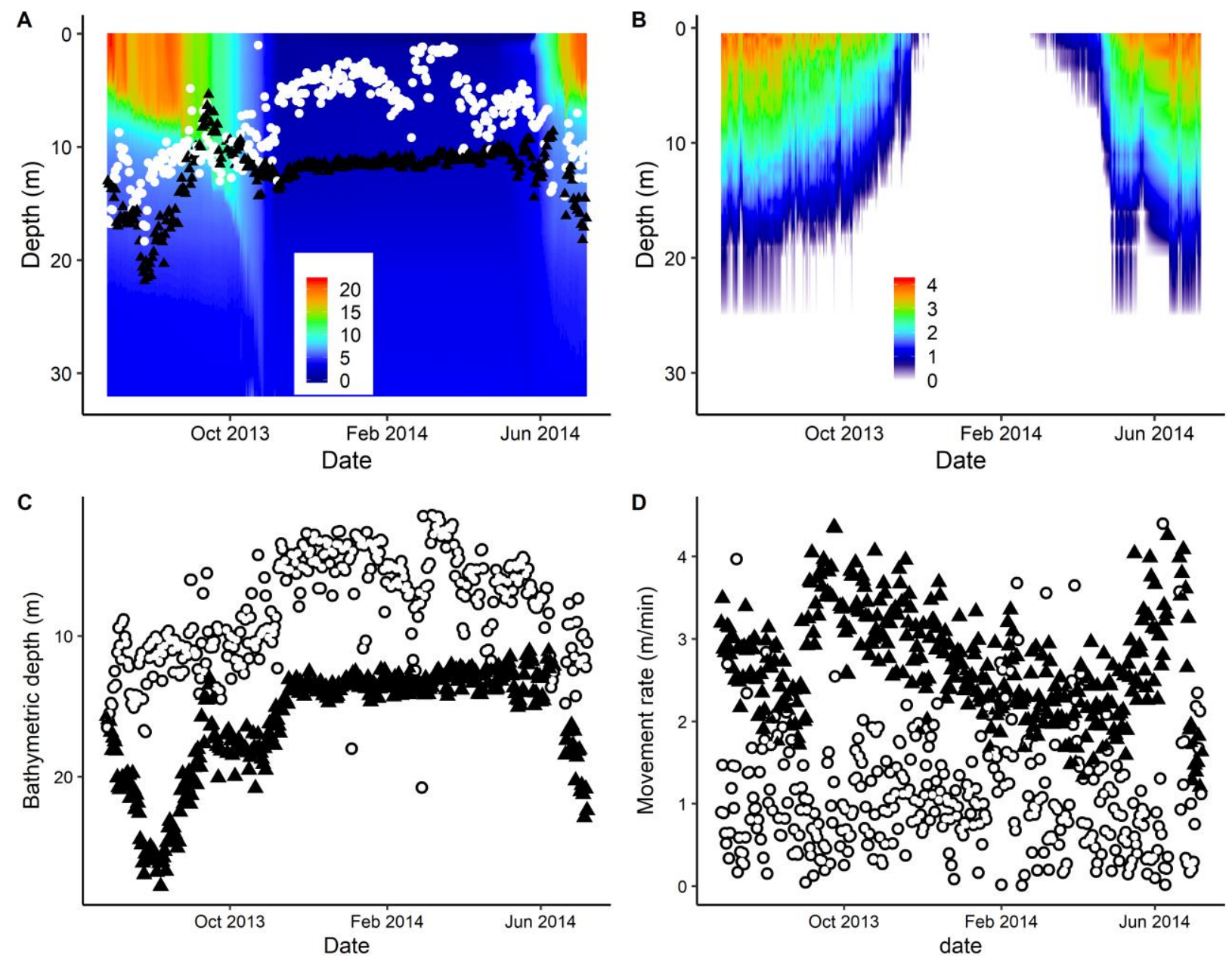
Figure 6. Densities of two competing species, one adapted to open water (red) and one to winter (blue) across a gradient of changing winter duration. Four cases were considered, where interspecific competition is either weak or strong in each season. Weak refers to a case where the two species coexist in a given season and strong refers to competitive exclusion in a given season (see Box 3 for detail).

\section{A. Open water weak, Winter weak}

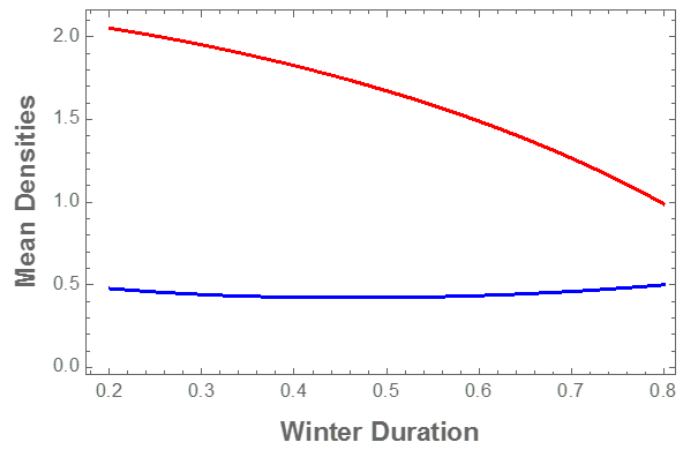

B. Open water strong, winter weak

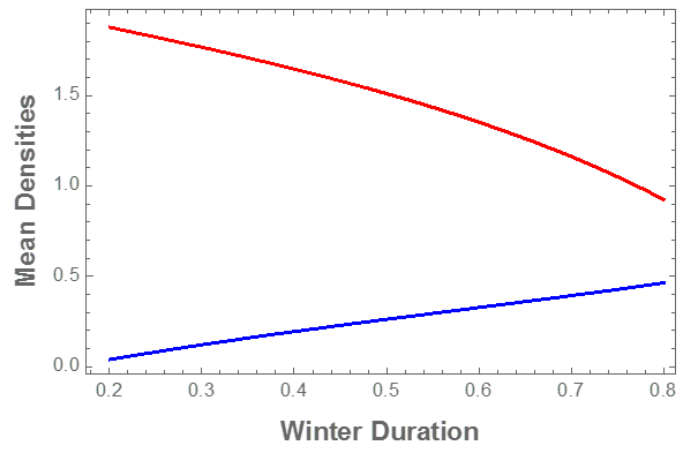

C. Open water weak, Winter strong

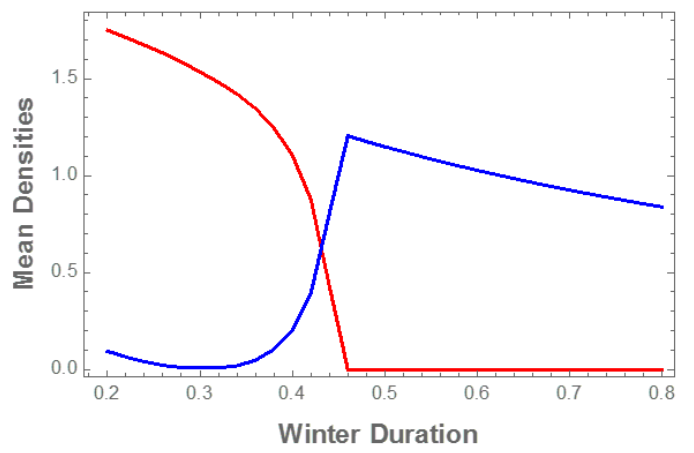

D. Open water strong, winter strong

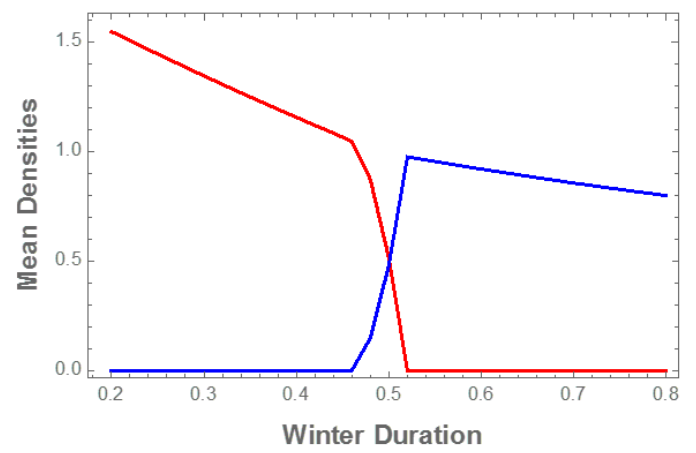

